\title{
高等学校实验技术队伍职业化路径研究
}

\author{
王志武 1 , 马国杰 ${ }^{1,2,{ }^{*}}$, 侯建华 1 , 刘学军 1 \\ 1 郑州大学实验室管理中心, 郑州 450001 \\ 2 郑州大学管理工程学院, 郑州 450001
}

\begin{abstract}
摘要: 高校实验室是 “立德树人” 的重要阵地, 实验技术队伍是实现 “三全育人” 的重要保障。高校快速发展过程中, 对实验技术队伍赋予了建设和管理的多重任务, 而自身缺乏明确的发展方向和目标, 实验技术队伍职业化研究成为高校 发展的现实需求。构建适应高等学校发展的实验技术队伍专业化管理体系, 明确实验队伍职业化发展路径选择的具体措 施, 促进实验技术队伍稳定性, 强化实验技术队伍在高等学校治理结构和提升内涵建设的有效作用, 为提升高校实验室 育人功能奠定基础, 为高等学校快速发展提供有力支撑。
\end{abstract}

关键词: 高等学校; 实验技术队伍; 专业化; 职业化; 路径

中图分类号: G647; O6

\section{Investigation into the Professionalization of the Experimental Technical Team at Colleges and Universities}

\author{
Zhiwu Wang ${ }^{1}$, Guojie Ma ${ }^{1,2,{ }^{*}}$, Jianhua Hou ${ }^{1}$, Xuejun Liu ${ }^{1}$ \\ ${ }^{1}$ Laboratory Management Center, Zhengzhou University, Zhengzhou 450001, China. \\ ${ }^{2}$ School of Management Engineering, Zhengzhou University, Zhengzhou 450001, China.
}

\begin{abstract}
A university laboratory is in an important position to "build morality and cultivate people", and the laboratory staff team can realize "three complete education". During the rapid development of colleges and universities, multiple tasks are assigned for the construction and management of the experimental team, while the individuals in the experimental team lack clear development prospects and goals. Research into professionalization of the experimental team is required for the development of colleges and universities. This paper proposes professionalization of the experimental team to adapt to the development of colleges and universities, to define the specific measures used to select the professional development path of the experimental team, to promote the stability of the experimental team, to strengthen the effective role of the experimental team in the governance structure of colleges and universities, and to enhance connections. This will contribute to the educational function of university laboratories and improve the quality of students, which provides strong support for the rapid development of colleges and universities.
\end{abstract}

Key Words: University; Experimental technical team; Specialized; Professionalization; Route

高校实验室是 “立德树人” 的重要场所, 也是人才培养、学科建设、科学研究、科技创新和大 学生 “双创” 的重要阵地, 而高素质的实验技术队伍是建设高水平实验室的基本保障 ${ }^{[1]}$, 是实现高 校 “双高” 发展的基本要素, 更是高校教学科研实力和一流人才培养的重要标志。如何建设一支富

收稿: 2021-09-24; 录用: 2021-09-27; 网络发表: 2021-11-15

“通讯作者, Email: wangzhiwu@zzu.edu.cn

基金资助：河南省高等教育教学改革研究与实践项目(2019SJGLX004); 中国高教学会2020年实验室重点专项课题(2020SYD03) 
有时代担当精神, 具有强烈责任感和奋斗精神的实验技术队伍, 成为高校强化治理能力和内涵化建 设的关键。

\section{1 高校实验技术队伍现状}

(1) 高校实验技术队伍主要包括从事实验教学、科研实验、仪器设备维护与管理等工作的人员, 一般由实验教师、实验技术人员、实验室管理人员和实验室技术工人组成。实验教师是指以实验教 学为主要职责的岗位; 实验技术人员是指以部分实验教学、实验指导、实验准备、仪器运行管理等 为主要岗位职责的人员; 实验室管理人员是指以实验室日常管理、协调等事务性管理工作为主要岗 位职责的人员；实验室技术工人是指从事实验准备及实验仪器保养等工作的工人。

（2）高校实验室的发展取决于实验技术队伍的整体素质，一流的实验室是一流大学的基本保障， 一流的实验技术队伍是一流实验室的重要支撑 ${ }^{[2]}$ 。新世纪以来, 我国高等教育实现了跨越式发展, 在学规模从 2000 年 909 万增长到 2019 年 3031 万, 稳居世界第一 ${ }^{[3]}$; 全国高等学校教职工由 130 万 增加到 257 万, 增长将近 1 倍。河南省 2013-2020 年专任实验技术队伍从 1432 人增加到 1599 人, 增长率 $11.7 \%$, 高校数量由 127 所增加到 151 所, 增长率 $18.9 \%$, 同期全省实验室数量增加 1.8 倍, 贵重仪器设备增加 6 倍。郑州大学 2011-2020 年实验技术队伍从 657 人降为 595 人, 其中专任实验 技术人员由 249 降为 200 人, 而同期学校大型仪器设备增加了 7 倍, 承担科研项目增加了近 3 倍。 高校实验技术队伍编制紧缺, 人员严重不足, 存在普遍学历偏低、年龄偏大, 专业性不强、缺乏创 新意识等情况 ${ }^{[1]}$, 而先进的仪器设备对实验技术队伍的要求也越来越高, 现有实验技术队伍越来越 难以满足高校发展的实际。

(3) 高校实验室工作是复杂的综合性工作, 实验技术队伍承担教学实验、科研实验和日常管理等 多重工作, 实验技术队伍是教学、科研的管理者、组织者、执行者和知识技能的传授者, 同时也是 负责实验室安全教育培训和安全直接责任人 ${ }^{[4]}$ 。多重工作压力下, 高校实验技术队伍存在一定的心 理压力和职业倦怠感，造成实验技术队伍流失严重，冲击实验技术队伍的稳定性 ${ }^{[5]}$ 。

(4) 近些年来, 高校重视学科发展, 在学科建设、高水平人才引进、大科学装置建设等方面投入了 巨额资金和大量人力, 但是对于实验技术队伍建设投入严重不足。学科发展和高水平科研成果具有 重要的显性价值, 对于提升高校的国内外学科知名度具有强烈的外溢优势, 因此高校对于提升学科 发展的显性价值投入很大, 引进大批高层次人才, 购买大量先进仪器设备等; 但是对基础实验技术 队伍建设提升学科发展内涵建设的隐性价值投入不足, 部分高校每年引进各类优秀博士体量都很大, 但是在实验技术人才引进方面却很少, 甚至部分高校几年未引进专职实验技术人才。而现有实验技 术队伍年龄结构严重老化, 专业知识结构不合理, 缺乏教育培训机制, 职业晋升通道狭窄, 学校管 理层面对于实验技术队伍重要性认识不足等问题, 严重制约实验技术队伍的职业化发展, 加强实验 技术队伍建设是强化高等学校内涵式发展的重要基础。

\section{2 实验技术队伍专业化建设}

(1) 高校实验技术队伍专业化建设是构建职业化路径的必然选择。实验技术的专业化建设是强 化高校实验实践教学、增强科研提升的内涵发展的必由之路。面对新时代高等学校人才培养 “以本 为本” 的强基要求, 面对与国际一流接轨的发展新目标, 面对利用 “互联网+” “大数据” 等开展开 放共享仿真实验教学的新态势, 面对高等教育国际化发展的新阶段, 高校实验技术队伍专业化建设 迫在眉睫。主动适应新时代高等教育发展要求, 从提升大学治理能力的内涵建设出发, 实验技术队 伍走向专业化和职业化的转变势在必行。

(2) 高校实验技术队伍的专业化建设不仅要求学校层面的重视, 更是实验技术队伍自身提升业 务能力和专业素质的内在要求。传统意义上的实验技术工作内容就是做好学生实验药品准备、调试 相关仪器设备、做好实验室日常管理、保障实验室安全运行等 ${ }^{[6]}$ 。新时代高等学校加强内涵建设, 赋 
予了实验技术队伍更大的工作职责, 实验技术队伍更是 “三全育人” 的有效支撑, 这就要求实验技 术队伍在做好传统意义上的工作的同时, 积极参与到人才培养和科学研究当中。实验技术队伍一方 面要丰富和改进实验教学内容, 另一方面更要在学生参与实验的过程中, 培养学生分析问题、解决 问题的能力, 提升培养学生的创新能力, 使之与高等学校教学改革相适应, 与培养高层次人才相结 合, 最大限度地发挥实验技术队伍在实验教学中的素质教育的引领作用 ${ }^{[7]}$ 。

(3) 高校实验技术队伍专业化建设就是要进一步加大实验教学改革创新, 以高校实验技术专业 化建设为基础, 积极开展实验技术职业化发展的实践探索。实验技术队伍专业化建设是实现实验教 学目标的有力保障, 学校要持续进行实验技术队伍的专业和技能培训, 实验技术队伍要加强自身学 习能力的提升, 要坚持以学生为本的育人理念和以教师为本的服务理念 ${ }^{[8]}$ 。随着高等教育改革发展 要求, 专业概念逐渐淡漠, 学科领域相互交叉渗透, 实验技术队伍必须拓宽知识领域, 了解学术前 沿, 不断学习新知识, 获得新思想, 将其转化为专业化能力的提升, 造就一支素质高、专业强、管 理好和一专多能的高素质实验技术队伍, 奠定实验技术队伍向专业化和职业化转变的坚实基础, 有 效促进实验室育人平台搭建和育人功能提升 ${ }^{[9]}$ 。

\section{3 实验技术队伍职业化路径}

实验技术队伍的职业化路径要明确自身在高校发展建设中的定位。实验技术队伍是高校建设和 发展的执行者, 是实验教学的执行者和管理者, 是实践教学的组织者, 是 “三全育人” 全员育人的 重要支撑, 是高校实验室安全运行的可靠保障, 是高校科学研究的重要基础保证。

\section{1 提升高校实验技术队伍的思想素质是实现职业化的认识基础}

实验技术队伍在高校一直以来以教辅身份参与各项工作，工作具有重复性、繁杂性，日复一日， 年复一年, 容易产生厌倦思想和职业倦怠。学校领导部门应从思想认识上重视实验技术队伍建设, 及时解决实验技术队伍存在的职称评审、晋升晋级等实际困难, 提升实验技术队伍的薪资待遇, 增 强实验技术队伍的内生动力。学院和实验室应加强实验技术队伍的思想政治工作, 提高实验技术队 伍的思想认识, 树立正确的人生观、价值观和苦乐观, 增强实验技术队伍的事业心和责任心。实验 技术队伍自身应当做好爱岗敬业的模范, 积极提升自身业务素质和业务能力, 做好学校发展的基础 保障。

\section{2 培养和强化实验技术队伍教学和科研能力是职业化的专业基础}

随着高等教育的快速发展, 知识更新加快, 实验技术队伍的知识也要不断充实和更新, 才能更 好地适应新时代高校教学改革的需要。实验技术队伍除做好实验准备工作外, 须具有娴熟的实验操 作技能和仪器设备的维护拓展能力, 实验技能的提升需要经过反复的实践和可靠的训练, 仪器设备 不仅要能进行一般性维护, 更要钻研仪器设备的功能拓展, 使之不仅为教学服务, 也能为高水平科 研服务。实验技术队伍一方面应积极参加教学、教研、教改活动, 提升实验教学服务能力, 另一方 面也要积极参加科研讲座和科研活动, 认真做好相关仪器设备对科学研究的支撑和服务。通过多种 形式的学习提升, 使之成为相关领域的专家, 不仅专业能力得到认可, 而且对于职务职称的晋升晋 级也大有禆益。

\section{3 明确高校实验技术队伍职责是职业化的制度基础}

高校实验技术队伍绩效考核面临学科多、实验技术工作内容和岗位职责不一致等问题, 如何界 定绩效考核的有效标准和量化方法, 能有效调动实验技术队伍的主观能动性, 是绩效考核的目标。 高校实验技术队伍绩效考核制度的建设应遵循实验技术工作的特点要求开展, 健全完善的绩效考核 制度建设是实验技术队伍绩效考核体系的根本 ${ }^{[8]}$ 。一是要遵循科学设计原则, 既要分析考核对象的 工作特点, 又要抓住考核对象的实质, 涵盖考核对象的工作内容 ${ }^{[10]}$; 二是遵循系统性原则, 针对考 核对象进行既相互联系, 又相互制约的考核指标进行评估; 三是遵循规范性原则, 考核制度体系设 计既要站在学校发展高度, 又要从实验技术工作的实际出发, 准确把握考核规范和考核尺度, 以最 
大程度地调动工作的内生动力为目标; 四是遵循实用性原则, 既具有制度规范性的刚性约束, 又要 把握考核尺度的弹性空间。

\section{4 健全实验技术队伍考核体系是职业化的重要保证}

当前高校实验技术队伍工作差异性很大, 文理工医专业性、仪器设备操作便捷性、教学科研服 务对象差异性, 以及个人考核和团队考核的协调性等。如何统筹绩效考核和运行保障, 既要保证考 核激励机制的有效性, 更要注重长期发展机制建设。高水平大学建设离不开稳定的实验技术队伍, 健全实验技术队伍的考核体系是职业化发展的必然要求。一是要运用社会学的角色理论引导社会、 家庭、学校等认可和尊重实验技术队伍的工作 ${ }^{[11]}$; 二是提升实验技术队伍的薪资福利待遇, 提高工 作满意度, 降低职业倦急感 ${ }^{[12]}$; 三是加强实验技术队伍的教育培训, 制定规范性要求强化队伍的专 业化学习和继续深造的机会, 激励他们的工作积极性; 四是健全和完善科学合理的考核评价机制, 推进公平合理的薪资福利制度, 构建符合实验技术队伍发展晋升的路径选择。既保证了队伍的稳定 性，同时又能吸引更多的高端优秀人才加入实验技术队伍，也为队伍职业化提供了重要保证。

\section{4 结语}

高等学校发展已经进入新的发展时期, 同时担负着重科技创新和人才培养的重要使命, 面向新 时代建设一支高水平的专业化实验技术队伍, 既是提升高等学校内涵建设的需求, 更是深化高等学 校治理能力的体现, 实验技术队伍的建设改革迫在眉睫。认清实验技术队伍发展存在的现实问题, 立足提升实验技术队伍专业化建设体系, 创新实验技术队伍职业化实现路径, 强化思想认识, 重视 制度体系建设, 健全绩效考核等策略, 构建 “引得来, 留得住, 干得好, 有发展” 实验技术队伍职 业化发展的特色路径, 有效促进和稳定高校实验技术队伍, 保障和助推高等学校快速发展。

\section{参 考 文 献}

[1] 郑雪红, 郑爱榕. 实验室研究与探索, 2011, No. 9, 334 .

[2] 邹岗. 实验室研究与探索, 2016, No. 12, 263.

[3] 张炜, 袁占亭, 刘献君, 卢晓中, 马陆亭. 中国高教研究, 2018, No. 7, 1.

[4] 刘友武. 赤峰学院学报, 2012, No. 12, 250.

[5] 余楠. 池州学院学报, 2018, No. 3, 143.

[6] 费骥慧, 黄玉峰, 周旋. 教育现代化, 2017, No. 17, 53.

[7] 㫿波. 实验技术与管理, 1994, No. 3, 11.

[8] 张旋, 张琦, 陶冬冰. 实验技术与管理, 2011, No. 7, 290.

[9] 王志武, 马国杰, 刘学军. 企业改革与管理, 2020, No. 9, 94.

[10] 吴竞梅. 解刨学杂志, 1993, No. 4, 378.

[11] 吴小玲. 卫生职业教育, 2008, No. 26, 36.

[12] 韦素娟. 黑龙江生态工程职业学院学报, 2019, No. 2, 95. 